\title{
Predictors of Neonatal mortality in Neonatal intensive care unit at referral Hospital in Southern Ethiopia: a retrospective cohort study
}

\author{
Tujare Tunta Orsido ${ }^{1}$, Netsanet Abera Asseffa ${ }^{2^{*}}$ (D) and Tezera Moshago Berheto ${ }^{2}$
}

\begin{abstract}
Background: The first one month of life; the neonatal period is the most risky time for child survival. In Ethiopia, neonatal mortality is unacceptably high, and the trend in reduction is slower as compared to infant and child mortality. The magnitude and associated factors of neonatal mortality in a tertiary care facility were not well documented. Therefore, the aim of this study was to determine neonatal mortality and predictors among neonates admitted to neonatal intensive care unit of Wolaita Sodo University Teaching and Referral Hospital, South Ethiopia.

Methods: A retrospective cohort study design was done among neonates admitted to neonatal intensive care unit of a University Teaching and Referral Hospital from 2015 to 2017. Data were collected using data extraction checklist from the medical registry. The main outcome was the occurrence of death within the first four weeks. The survival time was calculated in days between the date of admission and the date of death. Kaplan-Meier survival was used to depict the pattern of death in 28 days and Cox-Proportional model was used to identify the predictors of the neonatal mortality.

Results: A total of 964 neonates which contributed to 5889 neonates-days were included in the study. There were 159 neonatal deaths during the follow-up time. Overall, the neonatal mortality incidence was 27 per 1000 neonates-days. Predictors of neonatal mortality were: multiple birth, mothers who did not attend antenatal care visits, neonates born by cesarean section, not initiated breast feeding within $1 \mathrm{~h}$ of birth, neonates resuscitated, hyaline membrane disease and perinatal asphyxia.

Conclusion: Neonatal mortality at neonatal intensive care unit was high. Managing neonatal complications, initiating breast feeding within $1 \mathrm{~h}$ of birth, promoting antenatal care visits, improving quality of services and ensuring continuum of care are recommended to increase survival of neonates.
\end{abstract}

Keywords: Neonatal mortality, Neonatal intensive care unit, Ethiopia

\section{Background}

The first one month of life; the neonatal period is the most risky time for child survival. The world health organization reported 2.6 million deaths or roughly $46 \%$ of all under-five deaths occurred in 2016, up from $40 \%$ in 1990; nevertheless, neonatal mortality fell by $49 \%$ from 37 deaths per 1000 live births in 1990 to 19 in 2016 [1-3]. Ethiopia is one of the ten countries which

\footnotetext{
* Correspondence: aberanet@gmail.com

${ }^{2}$ School of Public Health, Wolaita Sodo University, 138 Wolaita Sodo, Ethiopia Full list of author information is available at the end of the article
}

accounts to two-third of global neonatal death and also among the six countries accounting half of global under five deaths [3,4]. Although developing countries have been given highest priority to achieve the global target of less than ten deaths per 1000 live births by 2035; it is projected that the sub-Saharan Africa will have 33\% of births and $60 \%$ of deaths in 2030, compared to $25 \%$ births and 50\% deaths in $2013[5,6]$.

The world has made substantial progress in reducing under five deaths from causes such as diarrhea, pneumonia and measles (3.3 million fewer deaths in 2013 versus

(c) The Author(s). 2019 Open Access This article is distributed under the terms of the Creative Commons Attribution 4.0 International License (http://creativecommons.org/licenses/by/4.0/), which permits unrestricted use, distribution, and reproduction in any medium, provided you give appropriate credit to the original author(s) and the source, provide a link to the Creative Commons license, and indicate if changes were made. The Creative Commons Public Domain Dedication waiver (http://creativecommons.org/publicdomain/zero/1.0/) applies to the data made available in this article, unless otherwise stated. 
2000). Nevertheless, congenital, preterm, neonatal sepsis and injury remain leading causes of death [6]. Several previous studies have identified a number of predictors that lead to neonatal deaths such as preterm birth (28\%), sepsis (26\%) and asphyxia (23\%). In developing countries, sepsis is the most common cause of neonatal mortality and is probably responsible for $30-50 \%$ of the total neonatal deaths each year $[1,7,8]$.

Literatures showed that neonatal mortality is the outcome of complex relationship between neonatal, maternal and health care-related factors. In spite of many efforts by the government and other partners, non-significant decline has been achieved in the last 20 years [ 9 , 10]. Between 1990 and 2015, the Ethiopia's neonatal mortality dropped from 63 to 23 per 1000 live births with annual fall of $2.2 \%$ [11]. According to EDHS (2016), Ethiopia is among the countries with the highest neonatal mortality with the rate of 29 deaths per 1000 live births. It is worth noting that $42 \%$ of the under- 5 mortality in Ethiopia is attributable to neonatal deaths [12, 13]. Identifying and understanding factors such as prenatal care, mode of delivery and labour can lead to reduction in neonatal mortality. Studies undertaken to assess the influence of these variables on neonatal mortality may have used descriptive designs which means fall in short to explain association [9]. It is useful to identify risk factors that predict early infant mortality, especially those that have the potential for intervention with modest resource [14].

The causes of neonatal mortality are not well documented in Ethiopia mainly at institutional level including this study area, but there are few studies that reported causes such as sepsis, asphyxia, preterm birth, congenital malformations [13]. With identification of risk factors, it is possible to prevent, particularly aiming the improvement of newborn children care. Here, the neonatal intensive care units (NICUs) is one of the most effective tools to reduce country's newborn mortality [15]. Therefore, this study assessed the predictors of neonatal mortality among neonates admitted to neonatal intensive care unit of Wolaita Sodo University Teaching and Referral hospital, southern Ethiopia.

\section{Methods}

\section{Study setting and period}

This study was done in Wolaita Sodo University Teaching and referral hospital, department of pediatrics from October 11-November 10, 2017. The university hospital serves more than three million people in Wolaita and neighboring zones. The pediatrics department had four major wings: pediatric Emergency admission unit, Neonatal Intensive Care Unit (NICU), pediatric surgical admission ward and pediatric medical admission ward. There were a total of 75 patient beds in the four wings; of which Neonatal ICU had 20 beds. The ICU was established in June, 2014 [16].

\section{Study design}

A retrospective cohort study design was conducted among admitted neonates.

\section{Source population}

All medical records of neonates admitted between October 2015 and October 2017 were included.

\section{Study population}

All records fulfilling the inclusion criteria from the source population.

\section{Sample size determination}

The sample size was calculated by using Open Epi-info version 3.03. The following considerations were made for the cohort study neonatal death was considered as an outcome variable and from predictors, single birth compared with multiple births. We assumed multiple birth as exposed and single birth as unexposed considering a 1.9 hazard-ratio [17]; $95 \%$ level of confidence and $80 \%$ power, the minimum sample size computed was 506. However, to improve the precision of the test the final sample size was 964 by including all neonates admitted to the NICU in the study periods.

\section{Inclusion criteria}

All neonates registered on neonatal registry book from October 2015 to October 2017 in Neonatal ICU of the teaching hospital were included.

\section{Exclusion criteria}

Neonatal medical record with incomplete information, age greater than 28 days and revisits were excluded from the study.

\section{Sampling techniques}

Neonatal medical record done from October 2015 to October 2017 in NICU of WSUTRH was retrieved by using data extraction checklist which was adopted from national neonatal registration book.

\section{Measurement}

Times- to- event, the event of interest was neonatal death.

\section{Exposure variables}

Maternal and Neonatal related factors: ANC follow-up, parity, gravidity, mode of delivery gestational age, birth weight, age of neonate at discharge, sex of neonate and temperature of neonate at admission. Neonatal illness during admission: respiratory distress, perinatal asphyxia, 
sepsis, congenital malformation, hyaline membrane disease, meconium aspirated syndrome. Care/service related factors: newborn resuscitated, initiation of breast feeding, treatment given and length of stay.

\section{Data collection procedure and quality assurance}

Data was abstracted by three trained nurses who had diploma and experience in the setting. The overall data collection process was supervised by trained BSc nurse. She was trained on how to revise the registry and then abstract secondary data from medical records. The principal investigator used to supervise by using data extraction checklist.

\section{Data management and analysis procedures}

Death of neonate was the event of interest which was coded as "1" for failure and "0" for censored. Time-to-event was calculated by subtracting the date of admission from the date of event. Data was entered into Epi-Data version 4.0.1.44 and exported to SPSS 20 for the analysis. The two dataset entered were validated for consistency and 7\% error was corrected from the original questionnaire. Frequencies, percentages and rates were computed. Analysis was carried out for explanatory data. Moreover, multi-colinearity was checked using correlation coefficient ( $\mathrm{r}$ ) and value of $r<0.7$ was used as a cutoff point when two variables have bivariate correlation. There was bivariate correlaton between parity and gravidity, gestational age and prematurity with $r=0.84$ and $r=0.99$ were found respectively. Mean and standard deviation were computed for follow-up time and age of the cohort. Cox-Proportional hazard model was used to determine factors associated with the survival time of neonates admitted in the NICU.

Kaplan Meier curves were used to estimate survival time. Log Rank test was used to look statistical differences between the categories of variables. Statistical significance was declared at $p$-value $<0.05$. A summary statistics of proportions including hazard ratio and $95 \%$ confidence intervals as used. Screening of predictors of neonatal mortality was done by using bivariate Cox regression for each variable one at a time. Then, those variables with $p<0.25$ during the bivariate Cox regression analysis were taken as a candidate variables for multivariate Cox regression model to control possible confounders.

\section{Results}

During the two years of observation, 1026 neonates were admitted at WSUTRH Neonatal ICU, followed for 5889 neonate event free days. The records of 62 neonates were excluded because of predetermined exclusion criteria; $39(3.8 \%)$ incompleteness, $15(1.5 \%)$ age above 28 days and $11(1.1 \%)$ revisits. Therefore, the present study included records of 964 neonates with optimally complete information. The mean $( \pm \mathrm{SD})$ length of stay at NICU was 6.1(5.1) days. Of the 964 neonates $752(78 \%)$ were discharged when their condition improved, 159(16.5\%) died, 29(3\%) went against medical advice, $21(2.2 \%)$ referred to another hospital after their primary reason for admission was managed in the unit and $2(0.3 \%)$ no change (those with terminal conditions).

\section{Neonatal and maternal characteristics}

Out of 964, 574(59.5) were male neonates making the male to female ratio 1.5:1. The mean $( \pm \mathrm{SD})$ age of neonate at discharge was 6.5(5.4) days. More than half $561(58 \%)$ were age less than 7 days. Majority $752(78 \%)$ of neonates were term. Among all admitted neonates $528(54.8 \%)$ were born from multiparous mothers and 452(46.9\%) neonates were born from mothers with Antenatal Care four and above visits (Table 1).

\section{Neonatal illness and service related factors}

The most common problem identified at admission was neonatal sepsis 554(57.5\%) followed by respiratory distress $422(43.8 \%)$ while the least common was congenital malformation 38(3.9\%) (Fig. 1). Concerning breast feeding, 519(53.8\%) neonates were breast fed within 1 hour of birth.

\section{Neonatal outcome}

During the study period, a total of $16.5 \% \quad(n=159)$ deaths of neonates were recorded. Of the 159 neonatal deaths, $132(83 \%)$ or 77 neonatal deaths per 1000 neonate-days were early neonatal mortality (0-6 days) and $27(17 \%)$ or six neonatal deaths per 1000 neonate-days were late neonatal deaths (7-28 days) (Fig. 2). The overall incidence of neonatal mortality was 27 neonatal deaths per 1000 person- days (95\% CI: 23.1, 31.5).

There was a lower level of late neonatal mortality rate compared to early neonatal mortality rate. It shows a significant decline in mortality after neonates survive the first 7 days of life in the observation period (Fig. 2). In the study out of the total admission, male deaths $112(11.6 \%)$ outnumbered female deaths $47(4.9 \%)$. Hyaline membrane disease $31(66 \%)$, perinatal asphyxia $58(22 \%)$ and congenital malformation 2(5.3\%) were identified as the leading causes of death during admission.

\section{Predictors of neonatal mortality in NICU of WSUTRH, South Ethiopia, 2015-2017}

The Variables that were found to have association with the death of neonates during bivariate Cox regression were: sex of neonate female, birth weight of neonate < $2500 \mathrm{~g}$, gestational age of neonate preterm, multiple birth (Table 2). 
Table 1 Frequency of neonatal and maternal factors of neonates admitted to WSUTRH, South Ethiopia, from 2015 to 2017

\begin{tabular}{|c|c|c|c|}
\hline Variables & Categories & Frequency & Percentage \\
\hline \multirow[t]{3}{*}{ Mode of delivery } & SVD & 602 & 62.4 \\
\hline & Assisted vaginal & 161 & 16.7 \\
\hline & $\mathrm{C} / \mathrm{S}$ & 201 & 20.9 \\
\hline \multirow[t]{2}{*}{ Birth weight of neonates } & $<2500 \mathrm{~g}$ & 333 & 34.5 \\
\hline & $=>2500 \mathrm{~g}$ & 631 & 65.5 \\
\hline \multirow[t]{2}{*}{ Birth level of neonates } & Single & 821 & 85.2 \\
\hline & Multiple & 143 & 14.8 \\
\hline \multirow[t]{3}{*}{ Temperature of neonate at admission } & $<35.5^{\circ} \mathrm{C}$ & 323 & 33.5 \\
\hline & $35.5-37.5^{\circ} \mathrm{C}$ & 579 & 60.1 \\
\hline & $>37.5^{\circ} \mathrm{C}$ & 62 & 6.4 \\
\hline
\end{tabular}

Multivariate Cox regression revealed that neonates of multiple births had 1.8 times higher risk of death than singleton neonates, AHR [95\%CI] 1.8[1.10-2.94] (Fig. 3). Neonates born from mothers who did not attend ANC visits during their pregnancy were six times at higher risk of death than neonates born from mothers who had ANC visits 4 and above AHR [95\%CI] 6.02[3.52-10.27]. Neonates born by cesarean section had a $66 \%$ lower risk of death as compared with spontaneous vaginal delivery (SVD) AHR [95\%CI] 0.34[0.19-0.61]. Neonates admitted with the problem hyaline membrane disease (HMD) and perinatal asphyxia (PNA) had two times and 1.8 times higher risk of death than their counterparts [95\%CI] $2.04[1.16-3.59]$ and $1.81[1.24-2.63]$ respectively.

Neonates who had temperature of $<35.5^{\circ} \mathrm{C}$ at admission had 1.6 times higher risk of death than neonates temperature at admission $35.5-37.5^{\circ} \mathrm{C}$ AHR [95\%CI] $1.58[1.06-2.34]$. Neonates who were resuscitated had two times higher risk of death than neonates who were not resuscitated AHR [95\%CI] 2.28[1.54-3.38] and those who were not breast fed within $1 \mathrm{~h}$ of birth had 2.6 times higher risk of death than their counterpart. AHR [95\%CI: 2.62[1.60-4.30] (Table 2).

\section{Discussion}

This study aimed to determine incidence rate of neonatal mortality and its predictors among neonates admitted to Neonatal ICU of WSUTRH. Accordingly, the incidence rate of neonatal mortality was 27 deaths per 1000 neonate-days [95\%CI: 23.1-31.5]. This finding is higher than retrospective studies conducted in NICU in the northern Ethiopia and other studies done in similar settings $[15,18,19]$. The reason might be that some of previous studies used data from only delivery room and others used from both delivery and neonatal intensive care units also might be related with the quality of service provided, while this study used data of those neonates only admitted to neonatal intensive care unit.

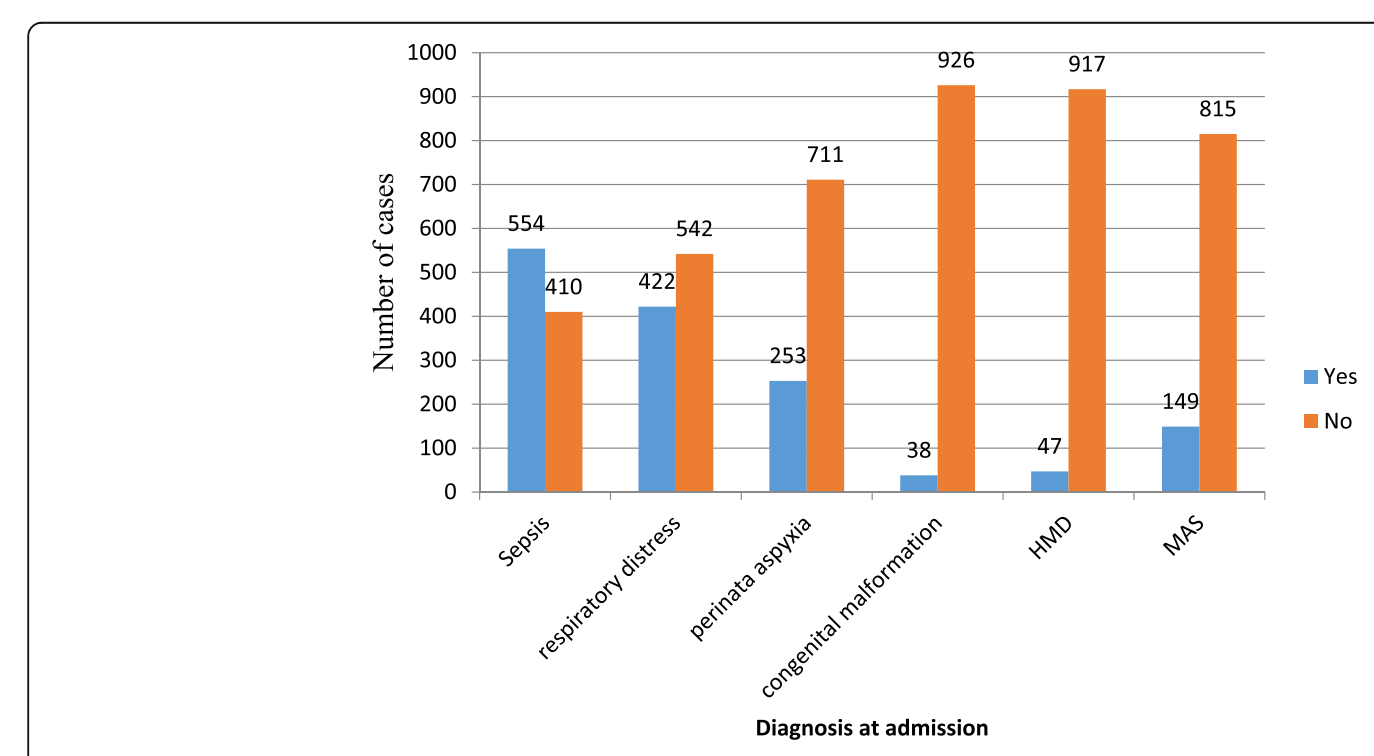

Fig. 1 Neonatal illness identified at admission in NICU of WSUTRH, South Ethiopia, 2015-2017 


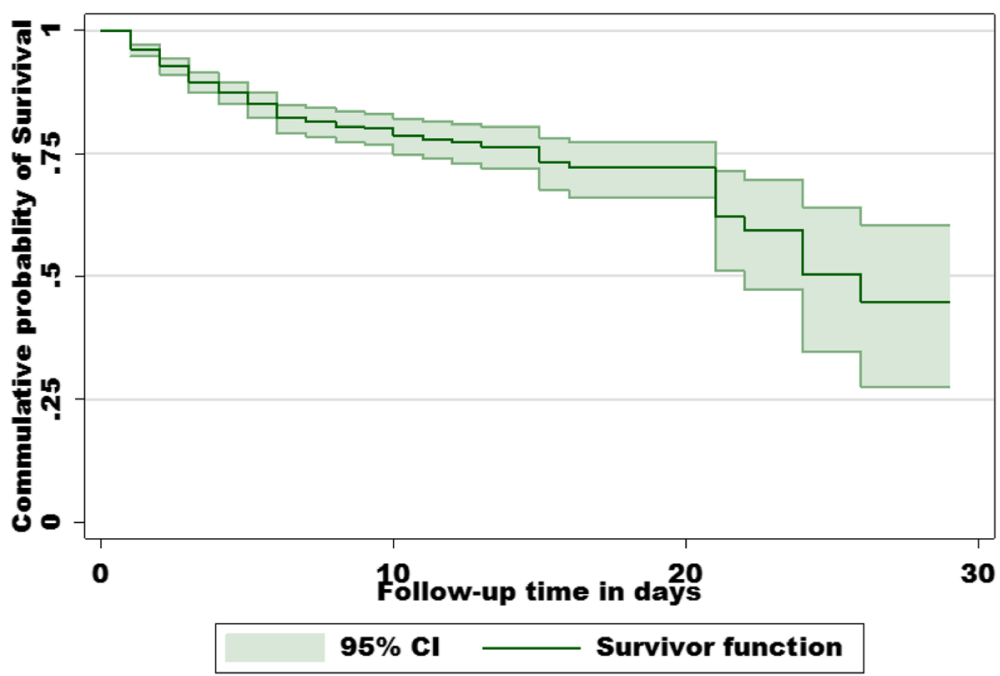

Fig. 2 K-M survival estimate of neonates hospitalized at NICU of WSUTRH South Ethiopia 2015-2017

Moreover, neonates transferred to Neonatal ICU for admission might have $\mathrm{r}$ risk of death as compared to those stayed with their mother in the delivery room [20].

This finding is lower than the study conducted using 5 years data (2001-2005) in NICU in the central Ethiopia where mortality rate was 233 per 1000 live births. This inconsistency might be related to the fact that this study used only perinatal period data-the first week of life. Moreover, it might be related to time difference as the government and partners have implemented several interventions in the last one and half decade. Moreover, the rate was lower than other studies conducted in Pakistan, Burkina Faso and Iran [21-23]. The difference could be that sources of data; these studies collected data from mothers who had different obstetric complications whereas this study did not consider that. And the other might be difference on study design. Neonates born from mothers who have complications during birth may have a higher chance of death. This study considered neonates admitted to NICU regardless of maternal status. This study is comparable with a trend analysis study done in Ghana [24].

In this study multiple births were at increased risk of death compared to neonate born singleton. This study is consistent with other studies done in tertiary hospitals in Ethiopia [25-27]. The multiple born neonates are at increased risk of prematurity and low birth weight, which may makes them susceptible to the risk of infection.

The findings of this revealed that those neonates born from mothers who had no ANC visit had six times higher risk of neonatal mortality as compared to those who had four and above ANC visits. This is similar to previous studies prospective studies done in Ethiopia [8, $9,28]$. The likely explanation could be that having ANC visit during pregnancy indirectly saves the lives of mothers and babies by promoting and establishing good health before childbirth and the early postnatal period [29]. Moreover, maternal health and health care are important determinants of neonatal survival. Based on the fact that neonatal outcomes are affected by maternal health throughout the pregnancy period; as result neonate born from mothers who had no ANC visits may have increased chance to be born with poor neonatal outcome.

This study revealed that mothers delivered by cesarean section had $66 \%$ protective effect on risk of neonatal mortality compared to SVD. This finding is comparable with studies conducted in Northwest parts of Ethiopia $[19,30,31]$. The possible explanation might be timely decision rather than waiting for vaginal delivery, delivering by $\mathrm{C} / \mathrm{S}$ can reduce the risk of death by decreasing the complications due to prolonged labour. This result is contrary with study conducted at Pakistan [7] whereby $\mathrm{C} / \mathrm{S}$ had increased neonatal mortality which could have resulted from decision making prolonged labour and poor quality of operation procedure. Moreover, it might be related to the outcome of $\mathrm{C} / \mathrm{S}$ which might hamper breast feeding practice. In this study, neonatal illnesses were one of the independent predictors for neonatal mortality. The causes of neonatal deaths were hyaline membrane disease and perinatal asphyxia. This is comparable with other studies conducted in Ethiopia and Ghana $[4,24,25]$. The possible reason is that in this study SVD outnumbered other mode of deliveries. It is known that SVD might happen after prolonged labour, hence it might led to respiratory complication.

The current study revealed that initiating breast feeding after 1 hour of birth has higher risk of neonatal mortality compared their counterpart. The finding is 
Table 2 Bivariate and Multivariate Cox-proportional hazard regression for predictors of neonatal mortality among neonates admitted to NICU of WSUTRH, South Ethiopia, 2015-2017

\begin{tabular}{|c|c|c|c|c|c|}
\hline \multirow[t]{2}{*}{ Variables } & \multicolumn{2}{|c|}{ Outcomes } & \multirow[t]{2}{*}{$p$-value } & \multirow[t]{2}{*}{ Crude HR 95\%Cl } & \multirow{2}{*}{$\begin{array}{l}\text { Adjusted HR } \\
95 \% \mathrm{Cl}\end{array}$} \\
\hline & event & censored & & & \\
\hline \multicolumn{6}{|l|}{ Sex of neonate } \\
\hline male & 112 & 462 & 1 & 1 & 1 \\
\hline Female & 47 & 343 & 0.003 & $0.59[0.42-0.84]$ & $0.91[0.64-1.30]$ \\
\hline \multicolumn{6}{|l|}{ Birth weight } \\
\hline$<2500 \mathrm{~g}$ & 104 & 229 & $<$ & $3.41[2.46-4.73]$ & $1.32[0.78-2.25]$ \\
\hline$>=2500 \mathrm{~g}$ & 55 & 576 & $\begin{array}{l}<0.001 \\
1\end{array}$ & 1 & 1 \\
\hline \multicolumn{6}{|l|}{ GA } \\
\hline term & 75 & 677 & 1 & 1 & 1 \\
\hline Preterm & 84 & 128 & $<0.001$ & 3.60 [2.63-4.93] & $0.92[0.48-1.78]$ \\
\hline \multicolumn{6}{|l|}{ Birth level } \\
\hline multiple & 69 & 74 & $<$ & $4.43[3.24-6.07]$ & $1.80[1.10-2.94]^{*}$ \\
\hline Single & 90 & 731 & $\begin{array}{l}0.001 \\
1\end{array}$ & 1 & 1 \\
\hline \multicolumn{6}{|l|}{ ANC follow-up } \\
\hline$>4$ & 19 & 433 & 1 & 1 & 1 \\
\hline $1-3$ & 60 & 286 & $<0.001$ & $4.06[2.42-6.81]$ & $2.76[1.62-4.71]$ \\
\hline None & 80 & 86 & $<0.001$ & 12.96 [7.86-21.39] & $6.02[3.52-10.27]^{* *}$ \\
\hline \multicolumn{6}{|l|}{ Parity } \\
\hline primipareous & 86 & 269 & $<0.001$ & $2.11[1.58-2.96]$ & 1.19 [0.86-1.66] \\
\hline Multipareous & 73 & 536 & 1 & 1 & 1 \\
\hline \multicolumn{6}{|l|}{ Mode of delivery } \\
\hline SVD & 136 & 466 & 1 & 1 & 1 \\
\hline SVD & 10 & 151 & $<0.001$ & $0.28[0.15-0.53]$ & $0.39[0.20-0.75]$ \\
\hline $\mathrm{C} / \mathrm{S}$ & 13 & 188 & $<0.001$ & $0.26[0.15-0.46]$ & $0.34[0.19-0.61]^{* *}$ \\
\hline \multicolumn{6}{|l|}{ Suspected sepsis } \\
\hline Yes & 106 & 448 & 1 & 1 & 1 \\
\hline No & 53 & 357 & 0.021 & $0.68[0.49-0.94]$ & $0.83[0.54-1.28]$ \\
\hline \multicolumn{6}{|c|}{ Respiratory distress } \\
\hline Yes & 74 & 348 & $>0.99$ & $0.0 .98[0.73-1.36]$ & - \\
\hline No & 85 & 457 & 1 & 1 & \\
\hline \multicolumn{6}{|l|}{ PNA } \\
\hline Yes & 58 & 195 & 0.001 & $1.73[1.25-2.39]$ & $1.81[1.24-2.63]^{*}$ \\
\hline No & 101 & 610 & 1 & 1 & 1 \\
\hline \multicolumn{6}{|c|}{ Congenital Malformation } \\
\hline Yes & 2 & 36 & 0.105 & $0.32[0.08-1.28]$ & \\
\hline No & 157 & 769 & 1 & 1 & - \\
\hline \multicolumn{6}{|l|}{ HMD } \\
\hline Yes & 31 & 16 & $<0.001$ & $4.60[3.10-6.82]$ & $2.04[1.16-3.59]^{*}$ \\
\hline No & 128 & 789 & 1 & 1 & \\
\hline \multicolumn{6}{|l|}{ MAS } \\
\hline Yes & 20 & 129 & 0.217 & $0.74[0.47-1.19]$ & \\
\hline No & 139 & 676 & 1 & 1 & - \\
\hline
\end{tabular}


Table 2 Bivariate and Multivariate Cox-proportional hazard regression for predictors of neonatal mortality among neonates admitted to NICU of WSUTRH, South Ethiopia, 2015-2017 (Continued)

\begin{tabular}{|c|c|c|c|c|c|}
\hline \multirow[t]{2}{*}{ Variables } & \multicolumn{2}{|c|}{ Outcomes } & \multirow[t]{2}{*}{$p$-value } & \multirow[t]{2}{*}{ Crude HR 95\%Cl } & \multirow{2}{*}{$\begin{array}{l}\text { Adjusted HR } \\
95 \% \mathrm{Cl}\end{array}$} \\
\hline & event & censored & & & \\
\hline \multicolumn{6}{|c|}{ Temperature of neonate at admission } \\
\hline $35.5-37.5$ & 42 & 537 & 1 & 1 & 1 \\
\hline$<35.5$ & 110 & 213 & $<0.001$ & $4.75[3.33-6.78]$ & $1.58[1.06-2.34]^{*}$ \\
\hline$>37.5$ & 7 & 55 & 0.343 & $1.47[0.66-3.28]$ & $1.58[0.70-3.59]$ \\
\hline \multicolumn{6}{|c|}{ Neonate resuscitated } \\
\hline Yes & 122 & 327 & $<0.001$ & $4.49[3.10-6.49]$ & $2.28[1.54-3.38]^{* *}$ \\
\hline No & 37 & 478 & 1 & 1 & 1 \\
\hline \multicolumn{6}{|c|}{ Breast feeding initiated } \\
\hline within $1 \mathrm{~h}$ & 22 & 497 & 1 & 1 & 1 \\
\hline after $1 \mathrm{~h}$ & 137 & 308 & $<0.001$ & $7.42[4.73-11.64]$ & $2.62[1.60-4.30]^{* *}$ \\
\hline \multicolumn{6}{|c|}{ Treated by oxygen } \\
\hline Yes & 139 & 477 & 1 & 1 & 1 \\
\hline No & 20 & 328 & $<0.001$ & $0.27[0.17-0.43]$ & $0.65[0.39-1.06]$ \\
\hline \multicolumn{6}{|c|}{ Treated by KMC } \\
\hline Yes & 53 & 108 & $<0.001$ & 2.22 [1.59-3.09] & $0.81[0.52-1.28]$ \\
\hline No & 106 & 697 & 1 & 1 & - \\
\hline \multicolumn{6}{|c|}{ Treated by antibiotics } \\
\hline Yes & 145 & 720 & 1 & 1 & - \\
\hline No & 14 & 14 & 0.93 & $0.97[0.63-1.69]$ & \\
\hline \multicolumn{6}{|c|}{ Treated by glucose } \\
\hline Yes & 54 & 268 & 0.97 & $1.01[0.72-1.40]$ & \\
\hline No & 105 & 697 & 1 & 1 & - \\
\hline
\end{tabular}

${ }^{* *} p<0.001,{ }^{*} p<0.05$, CHR-crude hazard ratio, AHR-adjusted hazard ratio and CI-confidence interval. $n$ was the same for the crude and adjusted models

comparable with a prospective study done in Ethiopia [25]. The timely initiation of breast feeding is essential to reduce newborn death [20]. However, in current study, initiating breast feeding within 1 hour of birth seems inadequately practiced and promoted. It is worth to note that neonates who are sick might not be able to suck breast milk as compared to healthier neonates.

The current study showed that resuscitating neonates in NICU has increased risk of death compared to their counterpart. This may be related to the fact that neonates being transferred to NICU might be at increased risk of neonatal complication or it might be related with using improper procedure to resuscitate and also may be the commitment of care provider. In addition, it might be related to the fact the hospital had comprehensive nurses who have not had adequate clinical attachment and/or experience on neonatal resuscitation. No other studies showed such kind of association.

The limitations of the study is that there is a potential to miss neonatal deaths particularly those registries considered as incomplete which would underestimate the overall neonatal mortality. The other limitation is that some important predictors of neonatal mortality were not explored because of missing data and lack of information.

\section{Conclusion}

There was high incidence of neonatal mortality in Wolaita Sodo University teaching and referral Hospital, which seekuns due attention in order to meet the goal of child survival in Ethiopia- reducing from 28 per 1000 in 2013 to 11 per 1000 live births in 2020. Multiple births, neonates born from mothers who did not attend ANC visit, neonates delivered by SVD, initiating breast feeding after 1 hour of birth, neonates with hyaline membrane disease and Perinatal Asphyxia, and resuscitating were significant predictors of neonatal mortality.

The neonatal intensive care unit should also work on early diagnosis and appropriate management at admission; and continuous care. The maternity ward should work on improvement within facility and others of catchment institutions to increase ANC visits, to improve obstetrics care services and early identification of severely asphyxiated neonates. Moreover, the hospital 


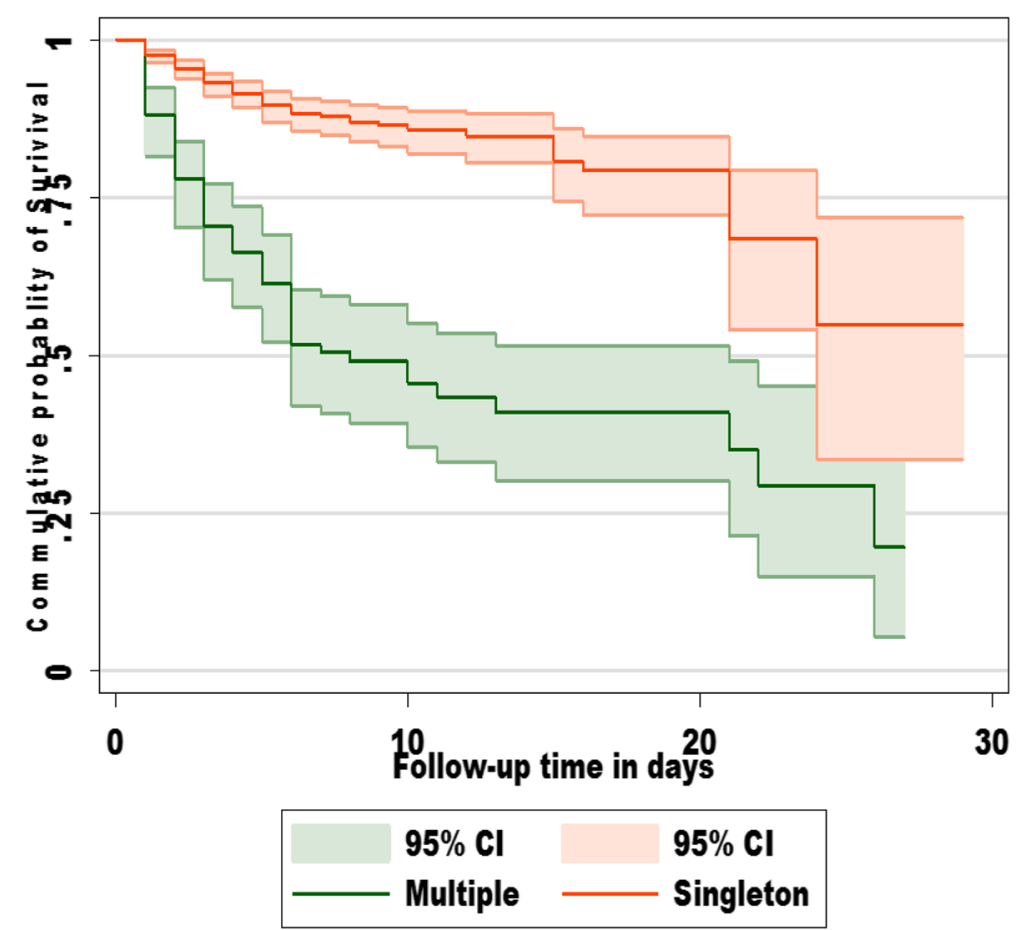

Fig. 3 K-M survival estimates of neonates by singleton status at NICU of WSUTRH 2015-2017

management should work to improve service provision at maternity ward and neonatal intensive care unit. Further studies using strong designs like prospective study should be conducted to explore more maternal, neonatal and care related factors.

\section{Abbreviations}

ANC: Antenatal care; AOR: Adjusted odds ratio; Cl: Confidence interval; EDHS: Ethiopian demographic and health survey; ETB: Ethiopian birr; HDSS: Health and demographic surveillance system; HMD: Hyaline membrane disease; HR: Hazard ratio; IMR: Infant mortality rate; KMC: Kangaroo mother care, K-M- Kaplan Meier; LBW: Low birth weight; MAS: Meconium aspirated disease; NGO: Nongovernmental Organization; NICU: Neonatal Intensive Care Unit; NMR: Neonatal mortality rate; OR: Odds ratio; PNA: Perinatal asphyxia; SD: Standard deviation; SDG: Sustainable developmental goal; SPSS: Software package of social science; SSA: SubSaharan Africa; WHO: World Health Organization

\section{Acknowledgements}

We would like to thank Wolaita Sodo University for financial and administrative support. We are grateful to the data collectors. We also extend our appreciation to Neonatal ICU staff Nurses for facilitating the data collection.

\section{Funding}

The study was financially supported by Wolaita Sodo University; however it had no role in any part of the study.

\section{Availability of data and materials}

The dataset analyzed for the findings of this study are available with the corresponding author and can accessed by reasonable request.

\section{Authors' contribution}

TTO: Conceived the study. TTO, TMB and NAA designed the study, performed the statistical analysis and wrote up the manuscript. All authors read and approved for correspondence to publication.

\section{Competing interest}

The authors declare that they have no competing interests.

\section{Ethics approval and consent to participate}

Ethical clearance was obtained from Ethical Review Committee (ERC) at College of Health Sciences and medicine in Wolaita Sodo University (WSU) with ref. number ERC/SPH/234/15. This committee works with the National Review Board for Research Ethics at Ministry of Science and Technology in Ethiopia and also in line with Ethical Committee in Health Bureau of Southern Ethiopia. Thus, an official letter confirming Ethical clearance to conduct the research was written from the committee to Wolaita Sodo University, College of Health Sciences, Department of Pediatrics and child Health, Wolaita Sodo University Teaching Referral Hospital, and then permission letter obtained from hospital director to NICU staffs to co-operate during data collection. Prior to initiating we requested waiver of consent to participate which was approved by the ERC.

\section{Consent for publication}

Not applicable

\section{Publisher's Note}

Springer Nature remains neutral with regard to jurisdictional claims in published maps and institutional affiliations.

\section{Author details}

'Wolaita Sodo University Teaching and Referral Hospital, Wolaita Sodo, Ethiopia. ${ }^{2}$ School of Public Health, Wolaita Sodo University, 138 Wolaita Sodo, Ethiopia.

Received: 8 June 2018 Accepted: 21 February 2019 Published online: 28 February 2019

\section{References}

1. World Health Org. Newborns: reducing mortality 2018. http://www.who.int/ news-room/fact-sheets/detail/newborns-reducing-mortality. Accessed 14 Sept 2018. 
2. World Health Organization. Neonatal Mortality; situations and trends. 2016. http://www.who.int/gho/child_health/mortality/neonatal_text/en/. Accessed 10 Sept 2018.

3. United Nations Inter-agency Group for Child Mortality Estimation (UN IGME). Levels \& Trends in child mortality: report, vol. 2017. New York: Estimates Developed by the UN Inter-agency Group for Child Mortality Estimation', United Nations Children's Fund; 2017

4. Abdulghani ST, Lawas AK. Perinatal and neonatal mortality in Fallujah general hospital, Fallujah City, Anbar Province. West Iraq. Health J. 2012 4:597-600.

5. Ndombo PK, Ekei QM, Tochie JN, Temgoua MN, Angong FTE, Ntock FN, et al. A cohort analysis of neonatal hospital mortality rate and predictors of neonatal mortality in a sub-urban hospital of Cameroon. Ital J Pediatr. 2017; 43(1):1-8.

6. Liu L, et al. Global, regional, and national causes of child mortality in 2000 13, with projections to inform post-2015 priorities: an updated systematic analysis. Lancer. 2015 Jan 31;385(9966):430-40.

7. Aijaz N. Disease burden of NICU, at a tertiary care hospital. Karachi J Dow Univ Heal Sci Karachi. 2012;6(1):32-5.

8. Mengesha, et al. Survival of neonates and predictors of their mortality in Tigray region, northern Ethiopia: prospective cohort study. BMC Pregnancy Childbirth, 2016:16(202).

9. Debelew GT, Afework MF, Yalew AW. Determinants and Causes of Neonatal Mortality in Jimma Zone, Southwest Ethiopia: A Multilevel Analysis of Prospective Follow Up Study. PLoS One. 2104;9(9).

10. Central Statistical Agency (CSA). Ethiopia Mini Demographic and Health Survey (EMDHS), Addis Ababa, Ethiopia. 2014.

11. Adinew Y, et al. Childhood Mortality: Trends and Determinants in Ethiopia from 1990 to 2015-A Systematic Review. Hindawi, Advances in Public Health Volume 2017, Article ID 7479295.

12. Central Statistical Agency (CSA). Ethiopia Mini Demographic and Health Survey (EMDHS), Addis Ababa, Ethiopia. 2016.

13. Mekonnen $Y$, et al. Neonatal mortality in Ethiopia: trends and determinants. BMC Public Health. 2013;13:483.

14. Chao Li, Lingxia Zeng MJD and DW. Predictors for neonatal death in the rural areas of Shaanxi Province of northwestern China: a cross-sectional study. BMC Public Health 2015;15(5):387.

15. Risso SDP. Risk factors for neonatal death in neonatal intensive care unit according to survival analysis. Rev Bras Ter Intensiva. 2010;22(4):19-26.

16. College of Health Sciences and Medicine. CHSM strategic management plan. In: 2015-2020; 2015.

17. Demisse AG GM. Patterns of admission and factors associated with neonatal mortality among neonates admitted to the neonatal intensive care unit of University of Gondar Hospital. And therapeutics,. J Pediatr Health Med 2016; 8:57-64.

18. Shetal S, Zemichael O, Hong D. Factors associated with mortality and length of stay in hospitalised neonates in Eritrea, Africa: a cross-sectional study. BMJ Open 2012;2:000792.

19. Tewabe T, Mohammed S, Tilahun Y. Clinical outcome and risk factors of neonatal sepsis among neonates in Felege Hiwot referral hospital, Bahir Dar, Amhara regional state, north West Ethiopia: a retrospective chart review. BMC Res Notes. 10:265.

20. Federal ministry of health Ethiopia. Neonatal intensive care unit guideline, Ethiopia. 2012.

21. Hussain S. Neonatal Morbidity and Mortality Pattern in a Tertiary Care Neonatal Unit of a Teaching Hospital. Ann Pak Inst Med Sci. 10(1):7-11.

22. Diallo AH, Meda N, Ouedraogo WT, Cousens S, Tylleskar T. A prospective study on neonatal mortality and its predictors in a rural area in Burkina Faso: can MDG-4 be met by 2015? J Perinatol. 31: 656-63.

23. Basiri B, et al. Neonatal Mortality and its Main Determinants in Premature Infants Hospitalized in Neonatal Intensive Care Unit in Fatemieh Hospital, Hamadan, Iran. Journal of Comprehensive Pediatrics. 2015;6(3):e26965.

24. Siakwa M, Laryea T, Ankobil A DS and Ebu, N.. A five-year neonatal mortality trend in a Ghanaian Teaching Hospital after the implementation of strategies to achieve the Millenium Development Goal. Int J Paediatr Child Heal. 2(1)

25. Tekleab AM, Amaru GM, Yemisrach AT. Reasons for admission and neonatal outcome in the neonatal care unit of a tertiary care hospital in Addis Ababa: a prospective study. Dove Press, Research and Reports in Neonatology. 2016(6):17-23.
26. Mengesha, et al. Low birth weight and macrosomia in Tigray, Northern Ethiopia: who are the mothers at risk? BMC Pediatrics. 2017;17:144.

27. Asefa D, et al. Pattern of Perinatal Mortality among Deliveries at Jimma University Teaching Hospital, South-West Ethiopia. J Womens Health, Issues Care. 2016(5)

28. Mehretie Kokeb and Teshome Desta. Institution Based Prospective CrossSectional Study on Patterns of Neonatal Morbidity at Gondar University Hospital Neonatal Unit, North-West Ethiopia. Ethiop J Health Sci. 2016;26(1): 73-79.

29. World Health organization. Opportunities for Africa's Newborns. https:// www.who.int/pmnch/media/publications/oanfullreport.pdf. Accessed 11 Sept 2018.

30. Hoseini BL, Rakhshani MH. Assessment of neonatal mortality in the Neonatal intensive care unit in Sabzevar City for the period of 2006-2013. Electron Physician. 2015:7(7):1494-9.

31. Kebede B, et al. Prevalence and associated factors of neonatal mortality in North Gondar Zone, Northwest Ethiopia. Ethiop. J. Health Dev. 2012;26(2).
Ready to submit your research? Choose BMC and benefit from:

- fast, convenient online submission

- thorough peer review by experienced researchers in your field

- rapid publication on acceptance

- support for research data, including large and complex data types

- gold Open Access which fosters wider collaboration and increased citations

- maximum visibility for your research: over $100 \mathrm{M}$ website views per year

At BMC, research is always in progress.

Learn more biomedcentral.com/submissions 